\section{International Scientific Journal Theoretical \& Applied Science}

Victor Goldade

Doctor of Science (Eng), Professor, Francisk Skorina Gomel State University, Physical Department

Gomel, Belarus victor.goldade@gmail.com

Elena Tsvetkova $\mathrm{PhD}$, Docent, Francisk Skorina Gomel State University, Biological Department Gomel, Belarus tsvetkova@mail.ru

\title{
EXPERIMENTAL AND THEORETICAL INVESTIGATION OF POLARIZATION PROCESSES IN COLLOIDAL SYSTEMS
}

\begin{abstract}
A physical model of polarization processes is proposed for liquid-dispersed systems worked out on the example of solutions of polyvinyl butyral and colloidal barium ferrite. The experimental and theoretical kinetic curves of polarization and isothermal depolarization are given for different polarization modes (long-term polarization under low polarization current, multiple short-term cyclic polarization, high-current short-term polarization). The theoretical depolarization model is based on the relaxation phenomena generated by diffusion processes in the polarized liquid-dispersed systems.

Key words: dispersion medium, polyvinyl butyral, barium ferrite, current density, near-electrode layer

Language: English

Citation: Goldade V, Tsvetkova E (2017) EXPERIMENTAL AND THEORETICAL INVESTIGATION OF POLARIZATION PROCESSES IN COLLOIDAL SYSTEMS. ISJ Theoretical \& Applied Science, 04 (48): 108117.
\end{abstract}

Soi: http://s-o-i.org/1.1/TAS-04-48-18 Doi: crossef https://dx.doi.org/10.15863/TAS.2017.04.48.18

\section{Introduction}

Multi-component liquid-dispersed systems (LDS), or colloidal systems, are widespread in the natural environment and used in medical and industrial applications, as well as other areas of human activity [1]. These include polymer gels used to create materials with a complex of adjustable properties for medical equipment, electronics and instrument engineering; natural waters used in different technological processes or which are subject to conditioning and filtration; drilling and grouting fluids used in oil and gas well construction; and finally, biological body fluids - blood and blood serum, cerebrospinal and synovial fluids, urine and saliva (changes in the structure and properties of these fluids provide information on the health status of a human being). LDS investigation allows to simulate the mechanisms of target-oriented drug delivery, therapeutic action of medicinal agents, and generates new knowledge for development of matrices used to cultivate biotissues.

The methods to control structure and composition of colloidal systems according to their electrophysical characteristics [2-6] were widely used in the investigation of multi-component LDS which is explained by rich possibilities of the methodology for automated collection and computerized analysis of information. The main factors which define LDS behavior at electrophysical measurements are: size and concentration of particles, concentration of electrolytes, dielectric permittivity, charge and potential of the particles' surface, charge relaxation time.

The analysis of kinetic dependencies of depolarization current revealed the patterns of change in the structure of polyvinyl alcohol gels filled with gelatin, papaine and $\mathrm{Na}-\mathrm{CMC}$ (sodium carboxymethyl cellulose) [7-9], and solutions of polyvinyl butyral (PVB) [10] which provided for optimization of LDS compositions by criterion of their structural stability. It has been established that the stability factor is associated with existence of an electrical double layer on particles [11-12] and is determined by an additional electrostatic component of the wedging pressure and an entropy component of physicochemical interaction of components in the system. Thus, it is possible to make judgment on the structural stability of gel systems based on the analysis of polarization processes occurring in LDS when the current passes through them.

Study of LDS based on the polyvinyl alcohol or PVB alcohol solution filled with ferromagnetic substances showed that polarization properties of the system are determined by the status of the magnetic material (whether it is magnetized or not), nature of the space charge formation near electrodes and 
intensity of the polarization current. Increase in polarization current results in abrupt "depletion" of the solution (decrease in concentration of the filler particles in the volume), and the fan-shaped divergence of depolarization curves at repeated measurements is observed [13-14]. Physical modeling of polarization processes in LDS can broaden the concepts of polarization mechanisms in such systems.

The purpose of this work is experimental investigation and theoretical modeling of polarization-depolarization processes on the example of liquid-dispersed low-conductive "polyvinyl butyral alcohol solution - barium ferrite" (PVB-BF) system.

\section{Materials and methods of investigation}

The investigation was focused on PVB-BF model system. The choice of PVB is caused by its good solubility in alcohols and sensitivity to electromagnetic fields. PVB PSH-1 grade with molecular weight of (30-200) thousand (GOST 9439), ethyl alcohol (GOST 18300) and magnetized $\mathrm{BF}$ powder $\left(\mathrm{BaO} \cdot 6 \mathrm{Fe}_{2} \mathrm{O}_{3}\right)$ with hexagonal denselypacked crystal lattice and particle size of $1-4 \mathrm{mcm}$ (TU 6-09-591-81) were used. The magnetized BF is usually dispersed in a solution in the form of agglomerations of 5-6 particles. Concentration of PVB solution in alcohol was constant and equal to 7 wt \%. Concentration of barium ferrite in LDS amounted to $10 \mathrm{wt} \%$.

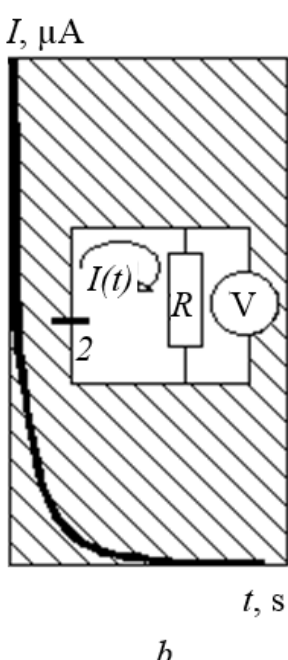

Figure 1 - Diagram for measuring polarization processes in liquid-dispersed systems: $a$ - polarization, $b$ depolarization. 1 - power source; 2 - measuring cell.

The experiments were held using a hardware and software suite - analyzer for disperse systems [15]. Method of isothermal depolarization (ITD) based on the charge relaxation in the polarized dielectric was employed in the study. ITD is one of the methods of complex electrophysical investigations to control LDS [4].

The system in question was placed into a measuring cell, then polarization current $I_{p}$ (current range from 100 to $1000 \mu \mathrm{A}$ ) was passed; during each experiment the intensity of current was kept unchanged by the feedback loop. Change in voltage over time $U(t)$ was registered at the cell (Fig. 1, a); this value is a variable which characterizes polarization of the system. Isothermal depolarization was carried out in the same cell by measuring depolarization current $I(t)$ (Fig. 1, $b$ ). In some cases, repeated (multiple) measurements of $U(t)$ dependencies were performed at specified equal time intervals $\tau$ (cyclic polarization-depolarization).

\section{Experimental results}

In the course of LDS polarization, voltage rises at the cell under polarization DC for any $I_{p}$ value (Fig. 2, a). Character of kinetic curves of LDS polarization differs from similar polarization dependencies for unfilled PVB solutions [6] by a section of intensive time-limited voltage rise. It is characteristic that the areas under the curve segments which characterize these sections are approximately equal for different polarization currents. This is an evidence of the fact that equal number of carriers really participate in the charge transfer, and the voltage rise at the cell is caused by concentration polarization due to the yield of particles from LDS volume and localization of the space charge in the thin near-electrode layer. 


\begin{tabular}{|c|c|c|c|c|c|c|}
\hline Impact Factor: & $\begin{array}{l}\text { ISRA (India) } \\
\text { ISI (Dubai, UAF } \\
\text { GIF (Australia) } \\
\text { JIF }\end{array}$ & $\begin{array}{l}=1.344 \\
=0.829 \\
=0.564 \\
=1.500\end{array}$ & $\begin{array}{l}\text { SIS (USA) } \\
\text { PИНЦ (Russia) } \\
\text { ESJI (KZ) } \\
\text { SJIF (Morocco) }\end{array}$ & $\begin{array}{l}=0.912 \\
=0.234 \\
=3.860 \\
=\mathbf{2 . 0 3 1}\end{array}$ & $\begin{array}{l}\text { ICV (Poland) } \\
\text { PIF (India) } \\
\text { IBI (India) }\end{array}$ & $\begin{array}{l}=6.630 \\
=1.940 \\
=4.260\end{array}$ \\
\hline
\end{tabular}
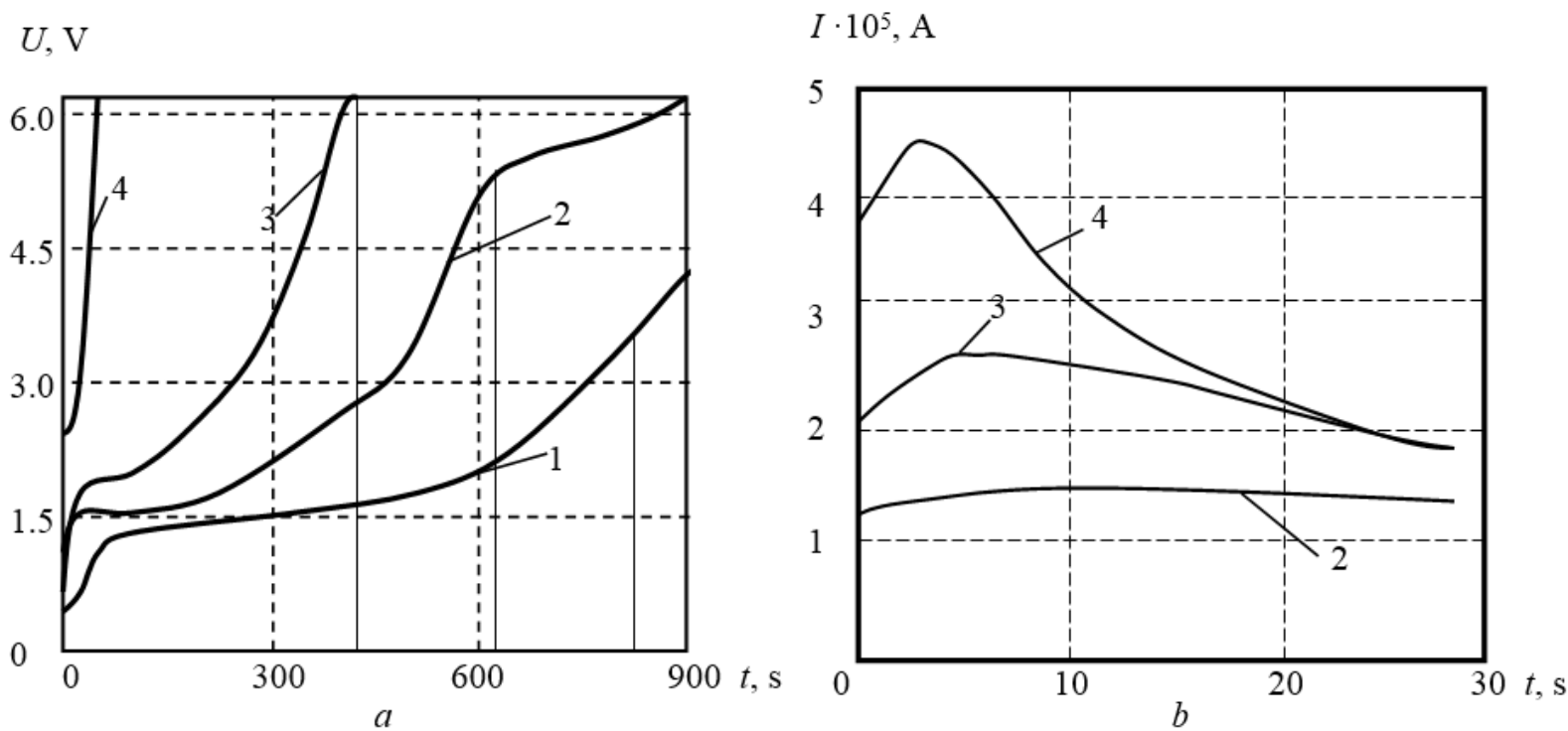

Figure 2 - Kinetic curves of the processes of polarization $(a)$ and depolarization $(b)$ in "PVB solution - BF" system under different polarization currents $(\mu \mathrm{A}): 1-100 ; 2-120 ; 3-200 ; 4-300$.

Measurement interval -200 ms.

End of the section of intensive voltage rise is an evidence of complete "depletion" of the solution and formation of the near-electrode charge layer. This process takes from several tens up to several hundred seconds (depending on the polarization current intensity) (Fig. 2, a).

Subsequent depolarization is characterized by extreme dependencies of the current over time (Fig. $2, b)$, and, with an increase in polarization current, the maximum on the depolarization curve moves to the area of lesser time values.

The state of the solution "depletion" can be reached both as a result of the repeated short-term "polarization-depolarization" cycles under low polarization currents (Fig. 3, $a, b$ ), and, almost immediately, under high polarization currents $I_{p}=1000 \mu \mathrm{A}($ Fig. $3, c)$.

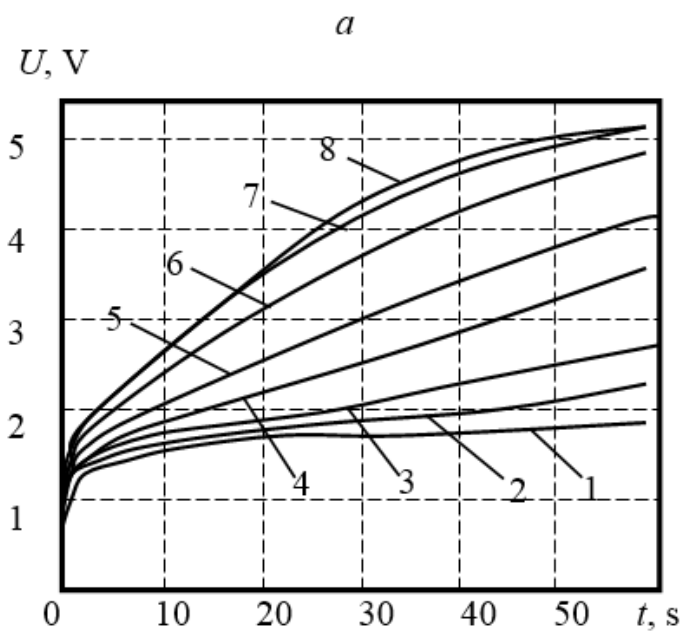

\section{I $\cdot 10^{6}, \mathrm{~A}$}

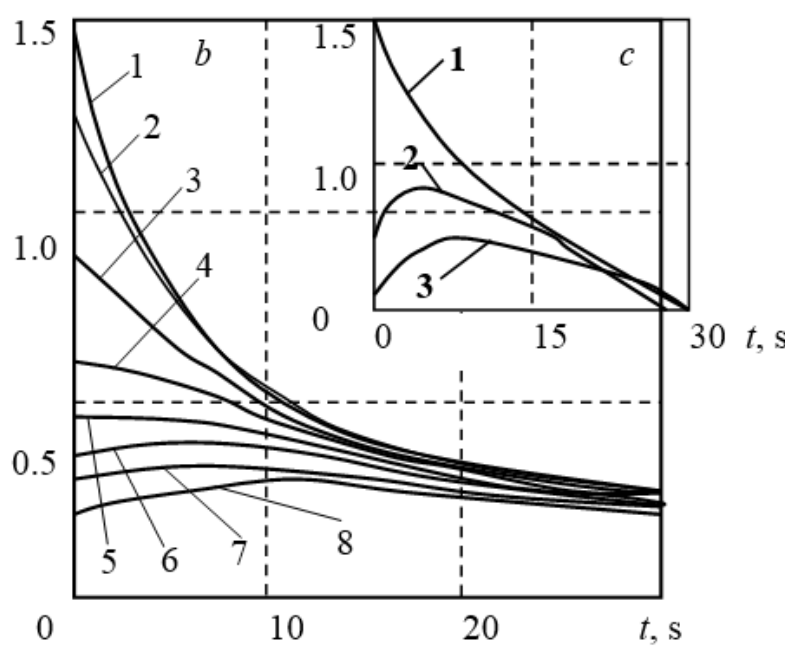

Figure 3 - Kinetics of the short-term cyclic polarization $(a)$ and depolarization $(b, c)$ in "PVB solution - BF" system under polarization currents $(\mu \mathrm{A}): a$ and $b-120, c-1000$. The curve numbers correspond to the cycle number.

Figure $3, b$ illustrates the process of extreme "depletion" of the system which has been reached at multiple repeated measurements at short intervals $(\tau$ $=180 \mathrm{~s}$ ). However, the same system status is also observed after a long continuous influence of polarization current, e.g., for 900 s. By comparing the system status after various polarization modes, the following may be noted: curve 3 in Fig. 3, $c$ (the 
result of short-term polarization at large $I_{p}$ values) corresponds to the final measurement under small polarization currents (a case of multiple short-term cycles, curve 8 in Fig. $3, b$ ) and identical to curve 2 in Fig. 2, $b$ which reflects the process of polarization in the system subjected to long-term polarization at small $I_{p}$ value. Thus, complete similarity of the depolarization curves characterizing the final status of the system, i.e. solution "depletion", is obvious. Insignificant deviations in absolute values of depolarization currents arise as the result of intrinsic difference between the individual samples that affect the accuracy of experiment.

\section{Theoretical model}

\subsection{Process of LDS polarization}

Since the current in the cell is kept constant, LDS conductivity decreases owing to the charge carriers which are localized in near-electrode areas of the measuring cell and cease to participate in the charge transfer. Linear change of conductivity over time as deduced from experiments [14] shows that the change in the number of carriers in the volume is governed by the following equation:

$$
N(t)=N_{0}-a t,
$$

where $N_{0}$ is the initial number of charge carriers in the cell, $a$ is a certain coefficient.

Due to linearity of the dependence of conductivity versus time, the number of charge carriers in the cell which drop out of the conductivity process per time unit is a constant value:

$$
\Delta N=I / q=\text { const }
$$

where $q$ is effective (average) charge of particle.

Then, the amount of particles involved in the conductivity at time $t$ is equal to:

$$
N(t)=N_{0}-\Delta N t=N_{0}-I t / q,
$$

In [14] it was noted that "the fan effect" (Fig. 3, a) begins to appear at the values of polarization current $I>I_{\text {cr }}$ (where $I_{\text {cr }}=100 \quad 120 \mu \mathrm{A}$ ) which corresponds to critical electric field intensity $E_{\mathrm{cr}}$ in the cell. Then the effective value $E_{e f}$ of the field intensity in the cell can be presented as

$$
E_{e f}=E-E_{c r}
$$

where $E$ is the external electric field intensity.

The increase in the specimen resistance under direct current means the decrease in the number of charge carriers capable to move in its volume under the influence of the external electric field. Assuming that a colloidal particle has a spherical shape, the current intensity in the cell, in the first approximation, can be determined by formula [16]:

$$
\begin{aligned}
& I(t)=q N(t) v(t)=q^{2} N(t) E(t) /(6 \pi \eta r)= \\
& =q^{2} N(t) U(t) /(6 \pi \eta r d),
\end{aligned}
$$

where $q$ and $r$ are the particle charge and conventional (effective) radius, $N(t)$ is the number of charge carriers in the sample at time $t, \eta$ is the medium viscosity, $E(t)$ is the average electric field intensity, $d$ is the distance between electrodes, $v(t)$ is the velocity of particles motion, $U=E / d$ is the voltage between electrodes.

On the basis of equations (3)-(5) we obtain an implicit equation for the current:

$$
I(t)=\frac{S q^{2} N\left(E-E_{\hat{\imath} \delta}\right)}{6 \pi \eta r}=\frac{\beta q^{2}}{d}\left(N_{0}-\frac{I(t) t}{q}\right)\left(U-U_{\hat{\imath} \delta}\right),
$$

where $S$ is the electrode area, $U_{c r}$ is the voltage corresponding to the critical electric field intensity,

$$
\beta=\frac{S}{6 \pi \eta r}
$$

is the coefficient which is constant for the given cell and the sample in question.

At $E<E_{c r}$ the BF particle remains motionless, the current in the system is caused by availability of the always-present ions of electrolytes (the dissociated polymer molecules and diverse admixtures) and the solution resistance slowly increases as its "depletion" accumulates. When the field intensity reaches $E_{\mathrm{cr}}$ value, the filler particles begin to move. Thus, the polarization current can be presented as the sum of two components: 1) quasiconstant admixture component and 2) the one associated with the particles motion in the solution:

$$
I(t)= \begin{cases}I_{0} \quad \text { at } & E<E_{c r} \\ I_{0}+I_{1} & \text { at } \quad E \geq E_{c r}\end{cases}
$$

where $I_{0}$ is the "admixture" current, $I_{1}$ is the current created by the disperse phase.

The experiment showed [15] that in the case of PVB solution without the filler, $I_{0}$ value also changes over time (although slightly), i.e. it should also be considered as a variable (but $E_{\text {cr }}$ is not available for it). Equation (6) taking into account equation (7) for the case $E \quad E_{\text {cr }}$ can be presented as follows:

$I(t)=\frac{\beta_{1} q_{1}^{2}}{d}\left(N_{01}-\frac{I(t) t}{q_{1}}\right) U+\frac{\beta_{2} q_{2}^{2}}{d}\left(N_{02}-\frac{I(t) t}{q_{2}}\right)\left(U-U_{c r}\right)$

where indexes " 1 " and " 2 " correspond to two types of physical charge carriers: " 1 " - to PVB solution, " 2 " - to BF particles.

The obtained expression (8) models the process of the current passing through the cell at LDS 


\begin{tabular}{|c|c|c|c|c|c|c|}
\hline Impact Factor: & $\begin{array}{l}\text { ISRA (India) } \\
\text { ISI (Dubai, UAE } \\
\text { GIF (Australia) } \\
\text { JIF }\end{array}$ & $\begin{array}{l}=1.344 \\
=0.829 \\
=0.564 \\
=1.500\end{array}$ & $\begin{array}{l}\text { SIS (USA) } \\
\text { PИНЦ (Russia) } \\
\text { ESJI (KZ) } \\
\text { SJIF (Morocco) }\end{array}$ & $\begin{array}{l}=0.912 \\
=0.234 \\
=3.860 \\
=\mathbf{2 . 0 3 1}\end{array}$ & $\begin{array}{l}\text { ICV (Poland) } \\
\text { PIF (India) } \\
\text { IBI (India) }\end{array}$ & $\begin{array}{l}=6.630 \\
=1.940 \\
=4.260\end{array}$ \\
\hline
\end{tabular}

polarization taking into account low conductivity of PVB solution and in the presence of macroscopic particles of the filler (BF) capable to move in the solution and to create the screening layer in the nearelectrode areas.

To obtain the dependence $U=f(I, t)$ which is a work expression allowing to numerically simulate the kinetics of LDS polarization it is necessary to evaluate values of $\beta$ coefficients and their products $\frac{\beta q^{2}}{d} N_{0}, \frac{\beta q}{d}$ and $q N_{0}$ which are included into formula (8). At the values $U<U_{\text {cr }}$ the second summand in expression (8), according to (7), becomes zero. Then

$$
U(t)=\frac{I(t)}{\frac{\beta_{1} q_{1}^{2}}{d}\left(N_{01}-\frac{I(t) \cdot t}{q_{1}}\right)}
$$

Values of experimental parameters of the polarization process given in Table 1 were used to calculate the coefficients.

Polarization mode parameters.

Table 1

\begin{tabular}{|c|c|c|}
\hline $\begin{array}{c}\text { Polarization current } \\
I, \mu \mathrm{A}\end{array}$ & $\begin{array}{c}\text { Polarization time } \\
t, \mathrm{~s}\end{array}$ & $\begin{array}{c}\text { Voltage at the cell } \\
U, \mathrm{~V}\end{array}$ \\
\hline \multicolumn{3}{|c|}{$P V B$ solution } \\
\hline 100 & 0 & 1.294 \\
\hline 100 & 90 & 1.361 \\
\hline \multicolumn{3}{|c|}{$P V B$ solution $+10 \% B F$} \\
\hline 200 & 900 & 4.604 \\
\hline
\end{tabular}

All coefficients with index "1" (for PVB solution without the filler) were calculated by formula (9). After substituting the obtained values of coefficients into formula (8) and taking into account the experimental value of critical voltage $U_{c r}=1.4 \mathrm{~V}$, we get the values of coefficients with index " 2 " (for ferrite-filled LDS). Values of the mentioned coefficients are given in Table 2.

The calculated values of coefficients.

Table 2

\begin{tabular}{|c|c|c|}
\hline$\frac{\beta q^{2}}{d} N_{0} \cdot 10^{5}, \frac{\grave{A}}{V}$ & $\frac{\beta q}{d} \cdot 10^{4},(\mathrm{~V} \cdot \mathrm{s})^{-1}$ & $q N_{0}, \mathrm{Kl}$ \\
\hline \multicolumn{3}{|c|}{$P V B$ solution } \\
\hline 7.72 & 4.22 & 0.183 \\
\hline \multicolumn{3}{|c|}{$P V B$ solution $+B F$} \\
\hline
\end{tabular}

Having substituted the calculated values of coefficients into formula (8), and after simple transformations we get the dependence $U=f(I, t)$ for various polarization modes:

$$
U(t)=\left\{\begin{array}{c}
\frac{10^{4} I}{0.772-4.22 I t}, \text { at } \quad U<U_{c r} \\
\frac{10^{4} I+(0.84-13.19 I t)}{1.37-13.64 I t}, \text { at } \quad U \geq U_{c r}
\end{array}\right.
$$

Herein, current $I$ is in amperes and time $t$ - in seconds.
The results of the polarization kinetic curves calculation by formula (10) are given in Fig. 4. It can be seen that theoretical curves are well in line with the experimental ones (Fig. 2,a) except for the initial section characterizing the conductivity of the dispersion medium (PVB solution) which was not taken into in the given model.

Therefore, the known characteristics of the dispersion medium (viscosity of solution) and the filler (size and concentration of particles) allow to evaluate in advance (before LDS preparation) the progress and key parameters of the kinetic curves of the polarization process. 


\begin{tabular}{l|lrl|l|ll} 
& ISRA (India) & $=\mathbf{1 . 3 4 4}$ & SIS (USA) & $=\mathbf{0 . 9 1 2}$ & ICV (Poland) & $=\mathbf{6 . 6 3 0}$ \\
Impact Factor: & ISI (Dubai, UAE) $=\mathbf{0 . 8 2 9}$ & PUHU (Russia) $=\mathbf{0 . 2 3 4}$ & PIF (India) & $=\mathbf{1 . 9 4 0}$ \\
& GIF (Australia) & $\mathbf{0 . 5 6 4}$ & ESJI (KZ) & $=\mathbf{3 . 8 6 0}$ & IBI (India) & $\mathbf{4 . 2 6 0}$
\end{tabular}

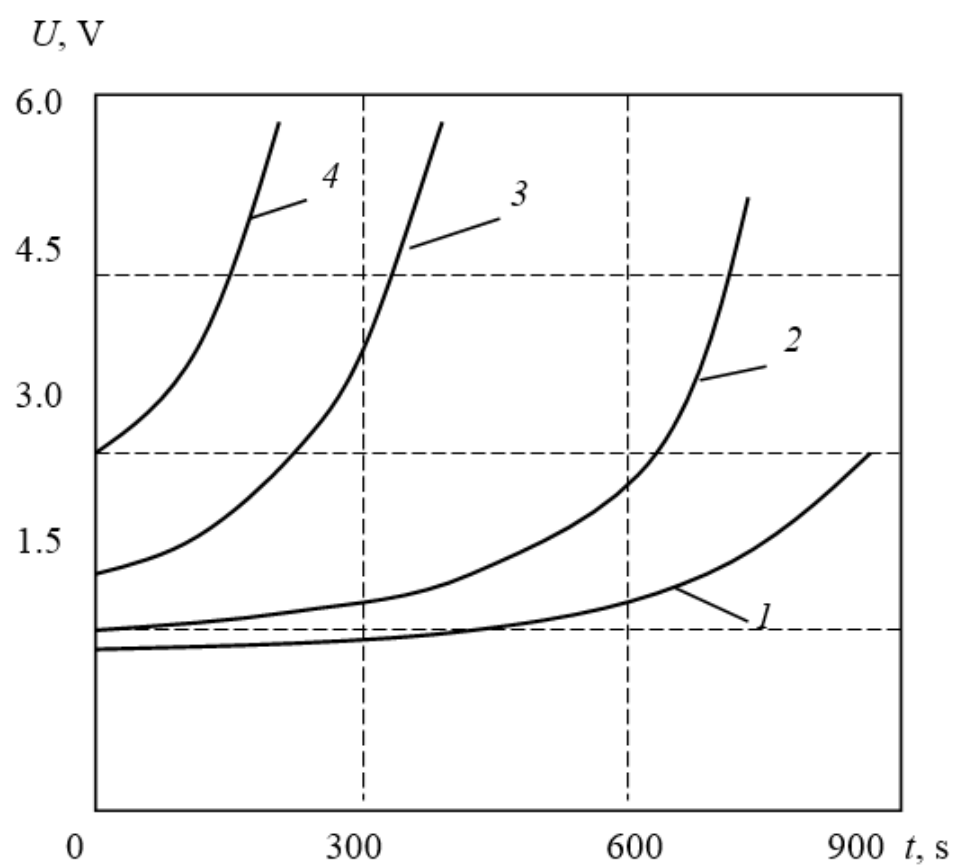

Figure 4 - Theoretical kinetic curves of the polarization process in "PVB solution - BF" system; polarization currents $I_{p}(\mu \mathrm{A}): 1-100 ; 2-120 ; 3-200 ; 4-300$.

Let's perform a qualitative study of the effect of the "fan" emergence at the consecutive "polarizationdepolarization" cycles at equal time intervals $\tau$ between measurements. In the course of the cell polarization, the space charge is formed in narrow near-electrode areas. In each cycle, when the external polarization voltage is disabled, the specimen represents a non-equilibrium system with excessive concentrations of charge carriers in the nearelectrode areas. At isothermal aging, scattering of charges occurs due to diffusion processes, and the specimen is depolarized. Leaving out of consideration the dissipative processes, let's establish the effect of isothermal aging on the nature of the "polarization-depolarization" process.

At the end of $t$ time period, particles will accumulate at the end of the electrode in the amount of It/q. We consider that the charges are absent outside the layer of $\delta$ thickness $\left(\delta \approx 10^{-6} \mathrm{~m}\right)$ [17]. The particles concentration will be equal to

$$
\tilde{n}(t)=\frac{I t}{q S \delta}
$$

where $S$ is the electrode area.

Considering that the amount of substance in the layer per unit area is $c(t) \cdot \delta S=I t / q=$ const, then the change in particles concentration over time $\tau$ in the process of isothermal aging can be described by the known formula [18, p. 431]:

$$
\tilde{n}(x, \tau)=\frac{I \tau}{q \sqrt{\pi D \tau}} \cdot e^{-\frac{x^{2}}{4 D \tau}}
$$

where $D=k T /(6 \pi \eta r)$ is the particles diffusion coefficient.

The system has particles of two characteristic dimensions: $\sim 10^{-8} \mathrm{~m}$ (PVB molecule) and $\sim 0.5 \cdot 10^{-7}$ $\mathrm{m}(\mathrm{BF})$. The following is observed in PVB alcohol solution $(\eta \approx 1 \mathrm{~Pa} \cdot \mathrm{s}): D \approx 2 \cdot 10^{-13} \mathrm{~m}^{2} / \mathrm{s}$ for $\mathrm{PVB}$ molecules, $D \approx 4.3 \cdot 10^{-16} \mathrm{~m}^{2} / \mathrm{s}$ for BF particles. For two consecutive time intervals $\tau_{1}$ and $\tau_{2}$ the concentration ratio will be as follows:

$$
\frac{\tilde{n}\left(\tau_{1}\right)}{\tilde{n}\left(\tau_{2}\right)}=\sqrt{\frac{\tau_{2}}{\tau_{1}}} \cdot e^{-\frac{\delta^{2}}{4 D} \cdot \frac{\Delta \tau}{\tau_{1} \tau_{2}}}
$$

Then, by substituting the values of the specified parameters into (13) and assuming that $\tau_{1}=1 \mathrm{~s}, \tau_{2}=$ $180 \mathrm{~s}$, we get the ratio $\alpha=c\left(\tau_{1}\right) / c\left(\tau_{2}\right)$ which determines by how many times the particles concentration will decrease in the near-electrode layer after isothermal aging of the cell for $180 \mathrm{~s}$. The particles concentration in the near-electrode layer at different points in time determines the amount of particles involved in the conductivity:

$$
\frac{\tilde{n}\left(\tau_{1}\right)}{\tilde{n}\left(\tau_{2}\right)}=\frac{N_{2}}{N_{1}}=\alpha \text {. }
$$




\begin{tabular}{|c|c|c|c|c|c|c|}
\hline Impact Factor: & $\begin{array}{l}\text { ISRA (India) } \\
\text { ISI (Dubai, UAF } \\
\text { GIF (Australia) } \\
\text { JIF }\end{array}$ & $\begin{array}{l}=1.344 \\
=0.829 \\
=0.564 \\
=1.500\end{array}$ & $\begin{array}{l}\text { SIS (USA) } \\
\text { PИНЦ (Russia) } \\
\text { ESJI (KZ) } \\
\text { SJIF (Morocco) }\end{array}$ & $\begin{array}{l}=0.912 \\
=0.234 \\
=3.860 \\
=\mathbf{2 . 0 3 1}\end{array}$ & $\begin{array}{l}\text { ICV (Poland) } \\
\text { PIF (India) } \\
\text { IBI (India) }\end{array}$ & $\begin{array}{l}=6.630 \\
=1.940 \\
=4.260\end{array}$ \\
\hline
\end{tabular}

Thus, $\alpha=4.29$ for PVB particles in the solution and $\alpha=0.6$ for BF particles.

As the polarization time in each cycle is the same, the value of discrete change in the carriers concentration in the cell volume is invariable, i.e. jt / $q=$ const. Some of the particles localized at the electrode after the first cycle of polarization return into the solution (as the result of diffusion), and by the end of isothermal aging during $\tau$ time the equation for the amount of particles in the cell taking into account (13) and (14) will be as follows (the second cycle):

$$
N_{02}=N_{01}-\frac{I t}{q}+(1-\alpha) \frac{I t}{q}=N_{01}-\alpha \frac{I t}{q}
$$

Correspondingly, the third cycle will give value $N_{03}=N_{01}-2 \alpha \frac{I t}{q}$, and for $k$-th cycle we'll get the resultant value $N_{0 k}=N_{01}-(k-1) \cdot \alpha \frac{I t}{q}$.

A consideration of this phenomenon allows to adjust calculation formula (10) for the case $U U_{c r}$ :

$$
U(t)=\frac{I \cdot 10^{4}+[0,84-(13,19+\alpha(k-1)) \cdot I t]}{1,37-[13,64+\alpha(k-1)] \cdot I t}
$$

Calculation by formula (16) gives an array of the fan-shaped curves (Fig. 5) corresponding to polarization curves observed in the experiment which have been repeatedly measured at equal time intervals (Figure 3,a).

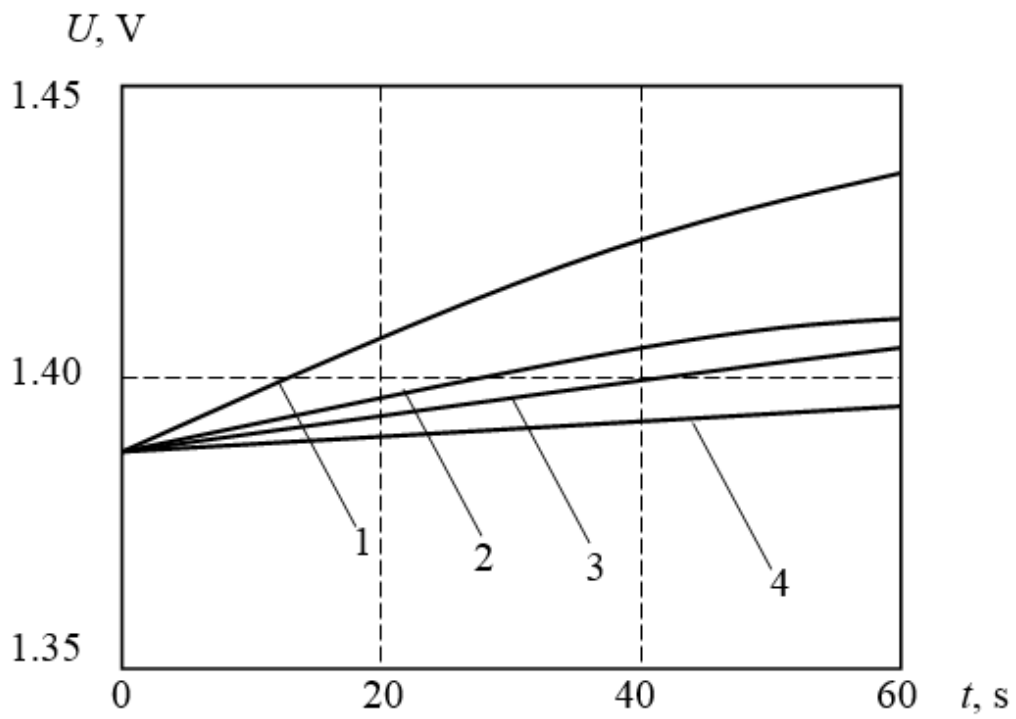

Figure 5 - Theoretical kinetic curves of the polarization process in "PVB-BF" system for polarization current of $110 \mu \mathrm{A}$ : The curve number corresponds to the cycle number (measurements with an interval of $180 \mathrm{~s}$ )

\section{LDS}

\subsection{Process of isothermal depolarization of}

Now let's study a physical model of the process of isothermal depolarization of LDS. The experimentally discovered phenomenon of the extreme behavior of depolarization current over time is an evidence that the system contains carriers of charges with different signs which create the nearelectrode charged areas of different size and charge in the process of polarization. According to $[19, \mathrm{p}$. 26], the depolarization current density in such system can be described by the equation:

$$
j=j^{+}-j^{-}=\frac{q_{+} n_{0}^{+} x_{0}^{+}}{2 d} \cdot \frac{d x^{+}}{d t}-\frac{q_{-} n_{0}^{-} x_{0}^{-}}{2 d} \cdot \frac{d x^{-}}{d t},
$$

where superscript indexes (+) and (-) refer to the values characterizing, respectively, positively and negatively charged near-electrode areas; $x_{0}$ is thickness of the near-electrode layer where the polarization charge is localized; $n_{0}^{( \pm)}$is its initial concentration; $\frac{d x}{d t}$ is the average velocity of the charges displacement. It should be noted that formula (17) is true if $\frac{x_{0}}{2 d}<<1$, i.e. the near-electrode areas of charges do not overlap which corresponds to the case of low-conductive LDS.

From the physical point of view the current density $j$ is determined by the sum of oppositely 


\begin{tabular}{|c|c|c|c|c|c|c|}
\hline Impact Factor: & $\begin{array}{l}\text { ISRA (India) } \\
\text { ISI (Dubai, UAF } \\
\text { GIF (Australia) } \\
\text { JIF }\end{array}$ & $\begin{array}{l}=1.344 \\
=0.829 \\
=0.564 \\
=1.500\end{array}$ & $\begin{array}{l}\text { SIS (USA) } \\
\text { PИНЦ (Russia) } \\
\text { ESJI (KZ) } \\
\text { SJIF (Morocco) }\end{array}$ & $\begin{array}{l}=0.912 \\
=0.234 \\
=3.860 \\
=\mathbf{2 . 0 3 1}\end{array}$ & $\begin{array}{l}\text { ICV (Poland) } \\
\text { PIF (India) } \\
\text { IBI (India) }\end{array}$ & $\begin{array}{l}=6.630 \\
=1.940 \\
=4.260\end{array}$ \\
\hline
\end{tabular}

directed currents. As a result of the process of depolarization when velocities of the charges "diffusion" are close to each other $\left(\left|\frac{d x^{+}}{d t}\right|=\left|\frac{d x^{-}}{d t}\right|\right)$, then, taking into account the values of the diffusion coefficients of the charge carriers, the dependence of the depolarization current versus time acquires an extreme character. For the case of the charge "diffusion" under study we will limit ourselves to the diffusion mechanism which is the major limiting factor in low-conductive systems.

During depolarization, a boundary of the nearelectrode layer moves away from the electrode into the cell volume. In this case, the particles concentration at distance $x$ from the electrode at time $t$ can be determined by the following formula $[18, \mathrm{p}$. 431]:

$$
n^{ \pm}(x, t)=\frac{n_{0}}{\sqrt{4 \pi D t}} \cdot e^{-\frac{x^{2}}{4 D t}}
$$

Each near-electrode charge cloud acts upon another (until they come in contact) as a single unit with the effective charge placed in the center of the cloud masses. Thus, it is possible to replace the polarized volume of substance in the cell with electric quasi-dipole with charges at the ends which are equal to the total charge of each near-electrode area; in this case, the charges are not equal in absolute values since the reactions on electrodes are asymmetrical.

Coordinates of the center of masses can be determined from the equation:

$$
x^{\prime}=\frac{1}{n_{0}} \int_{0}^{x} x \cdot n^{ \pm}(x, t) d x,
$$

or, taking into account (18) and subsequent transformations:

$$
x^{\prime}=\sqrt{\frac{4 D t}{\pi}}\left(1-e^{-\frac{x^{2}}{4 D t}}\right)
$$

By differentiating $x^{\prime}$ with respect to time and having made few transformations, we will get the velocity of displacement of the center of masses

$$
\frac{d x^{\prime}}{d t}=\frac{1}{2 t} \sqrt{\frac{4 D t}{\pi}}\left(1-e^{-\frac{3 x^{2}}{4 D t}}\right)
$$

which can be equated to the average velocities of the charges displacement $\frac{d x^{+}}{d t}$ and $\frac{d x^{-}}{d t}$ included into (17). Then, equation (17) will be as follows:

$$
j=a \frac{d x^{+}}{d t}-b \frac{d x^{-}}{d t}=\frac{a}{2 t} \sqrt{\frac{4 D_{1} t}{\pi}}\left(1-e^{-\frac{3 x^{2}}{4 D_{1} t}}\right)-\frac{b}{2 t} \sqrt{\frac{4 D_{2} t}{\pi}}\left(1-e^{-\frac{3 x^{2}}{4 D_{2} t}}\right)
$$

where $a=\frac{q_{+} n_{0}^{+} x_{0}^{+}}{2 d}, b=\frac{q_{-} n_{0}^{-} x_{0}^{-}}{2 d} ; D_{1}$ and $D_{2}$ are the diffusion coefficients of positively and negatively charged particles, respectively.

The value of the diffusion coefficients can be estimated by Einstein's formula [18, p. 433]:

$$
\sqrt{\Delta^{2}}=\sqrt{2 D \tau}
$$

where $\Delta$ is the mean displacement of the particle per time $\tau$. Assuming that $\Delta$ is equal to the distance between electrodes $(d=5 \mathrm{~mm})$, and particle displacement time $\tau \quad 30 \mathrm{~s}$, we get the value of the diffusion coefficient for PVB in solution $D_{1} \approx 10^{-5}$ $\mathrm{m}^{2} / \mathrm{s}$. In view of the laws of physics, it can be assumed that the diffusion coefficient for the ferrite particles is less for by at least 2-3 orders of magnitude, therefore we assume that $D_{2} \approx 10^{-8} \mathrm{~m}^{2} / \mathrm{s}$.

The numerical values of $a$ and $b$ coefficients in equation (22) are obtained by substituting values $q N_{0}$ from Table 2 and taking into account that thickness of the localization area for PVB is about $10^{-5} \mathrm{~m}$. The following values of coefficients were obtained: $a=4 \cdot 10^{-7} \mathrm{Kl} / \mathrm{m}^{3}$ and $b=0.85 \cdot 10^{-7} \mathrm{Kl} / \mathrm{m}^{3}$. It should be noted that coefficient $b$ changes discretely at consecutive cyclic measurements up to the limit value corresponding to the parameters in Table 2.

By assuming that $\mathrm{x}=0.5 \mathrm{~d}$ (the condition for contact of the diffusing near-electrode layers) and by substituting the values of all calculated coefficients into formula (22), it is possible to draw the kinetic curves of depolarization (Fig. 6). 


\begin{tabular}{l|lrl|l|ll} 
& ISRA (India) & $=\mathbf{1 . 3 4 4}$ & SIS (USA) & $=\mathbf{0 . 9 1 2}$ & ICV (Poland) & $=\mathbf{6 . 6 3 0}$ \\
Impact Factor: & ISI (Dubai, UAE) $=\mathbf{0 . 8 2 9}$ & PUHU (Russia) $=\mathbf{0 . 2 3 4}$ & PIF (India) & $=\mathbf{1 . 9 4 0}$ \\
& GIF (Australia) & $\mathbf{0 . 5 6 4}$ & ESJI (KZ) & $=\mathbf{3 . 8 6 0}$ & IBI (India) & $\mathbf{4 . 2 6 0}$
\end{tabular}

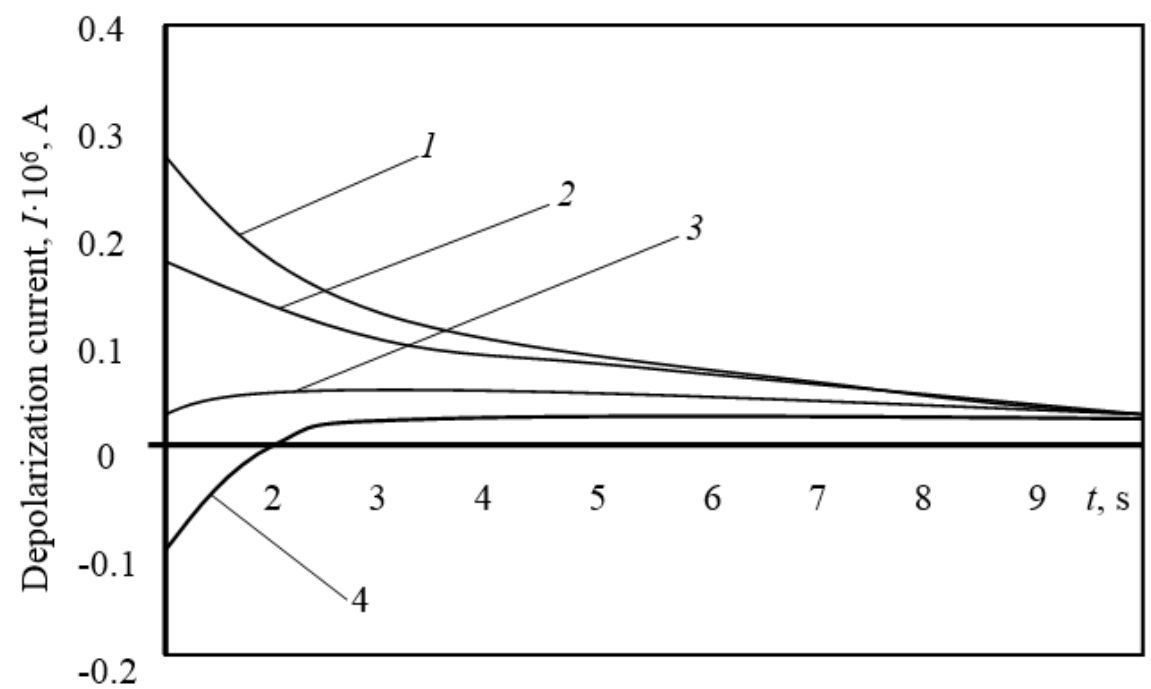

Figure 6 - Kinetic curves of the process of cyclic depolarization in "PVB solution - BF" system calculated for polarization current $I_{p}=100 \mu \mathrm{A}$. The curve number corresponds to the cycle number.

The character of calculated dependencies of the process of depolarization corresponds to the type of experimental curves (Fig. 3, b). Initial values of the calculated depolarization currents have an order of $10^{-7} \mathrm{~A}$, the values which have been actually observed during the experiments are $(0.3-1.5) \cdot 10^{-6}$ A. Taking account the aforementioned assumptions, the fit is quite acceptable.

Thus, despite a number of assumptions which have been made at creation of the given model (neglect of the real distribution of charges, conductivity gradient in the near-electrode areas, electrochemical processes on the surface of electrodes, orientation effects), it allows to evaluate and predict the type and specific nature of kinetic dependencies of the polarization-depolarization process in liquid-dispersed systems.

\section{Conclusion}

The proposed model has a phenomenological character and can be used as a basis for understanding of common patterns of polarizationdepolarization processes in liquid-dispersed systems and for planning the experiments.

Despite a number of assumptions which have been made at creation of the given model (neglect of the conductivity gradient in the near-electrode areas, electrochemical processes on the surface of electrodes, orientation effects), it allows to evaluate the nature and predict a type of kinetic dependencies of LDS polarization-depolarization process. To simplify the calculations, we have assumed the correlation between the diffusion coefficients and the size of the diffusing particles.

A limited number of measurements have been carried out for the process of polarization and the equation representing a multi-factor dependence (equation 8) is obtained. This equation represents the phenomenological model obtained from certain theoretical concepts, and coefficients have a scientifically-based physical meaning. Similar arguments can be given with respect to equation 16 . It should be noted that the calculated values in Figure 4 correspond to the experimentally obtained values (Fig. 2, a), and Figure 5 reflects the dependencies similar to the ones given in Figure 2, $b$.

The proposed phenomenological model of polarization-depolarization processes can be used as scientific justification of calculations of critical concentration of structure-forming components and methods to increase stability of the gel-polarized systems. Development of the model taking into account the size and electric properties of the anticipated components of colloidal system will allow, for example, to create means of target-oriented delivery of medicinal agents into the specified area of the body by releasing the medicine by depolarization of the colloidal structure; or to calculate permissible concentrations of target components in drilling fluids used in oil and gas well construction. 


\begin{tabular}{l|lrl|l|ll} 
& ISRA (India) & $=\mathbf{1 . 3 4 4}$ & SIS (USA) & $=\mathbf{0 . 9 1 2}$ & ICV (Poland) & $=\mathbf{6 . 6 3 0}$ \\
Impact Factor: & ISI (Dubai, UAE) $=\mathbf{0 . 8 2 9}$ & PUHL (Russia) $=\mathbf{0 . 2 3 4}$ & PIF (India) & $=\mathbf{1 . 9 4 0}$ \\
& GIF (Australia) & $\mathbf{0 . 5 6 4}$ & ESJI (KZ) & $=3.860$ & IBI (India) & $=\mathbf{4 . 2 6 0}$
\end{tabular}

\section{References:}

1. Dhirendra K, Lewis S, Atin K (2009) Solid dispersions: a Review. Pak. J. Pharm.Sci., 2009, Vol. 22, No. 2, pp. 234-246.

2. Delgado FV, Gonzales-Caballero F, Hunter RJ, Koopal LK, Lyklema J (2007) Measurement and interpretation of electrokinetic phenomena. J. of Colloid and Interface Science, 2007, Vol. 309, p. 194-224.

3. Soroka IF (1998) Electrophysiological investigation of blood serum of patients with rheumatic diseases in conjunction with virus hepatitis infection. Russian Gastroenterological Journal, 1998, No. 4, p. 22-28.

4. Shalamov IV, Ukhartseva IY, Tsvetkova EA, Goldade VA (2003) Investigation of electrophysical properties of liquid-dispersed systems by method of isothermal depolarization. Material Science (Materialovedenie), 2003, No. 3, p. 26-30.

5. Shalamov IV, Pinchuk LS, Ukhartseva IY, Tsvetkova EA (2001) Electrophysical method of liquid-dispersed systems monitoring. Materials. Technologies. Tools. 2001, Vol. 6, No. 2, p. 22-26.

6. Shalamov IV, Goldade VA, Tsvetkova EA (2007) Use of conductometric method at investigation of polymer solutions structure. Materials. Technologies. Tools. 2007, Vol. 12, No. 3, p. 94-101.

7. Ukhartseva IY, Shalamov IV, Tsvetkova EA, Pinchuk LS (1998) Polarization characteristics of filled gels on the base of polyvinyl alcohol. Plastic Masses, 1998, No. 6, p. 40-42.

8. Tsvetkova EA, Ukhartseva IY, Goldade VA, Shalamov IV (2016) Polarization processes in liquid-dispersed systems. Herald of the Technological University (Kazan), 2016, Vol. 19, No 5, p. 73-77.

9. Tsvetkova E, Ukhartseva I (2002) Electrophysical properties of gel systems based on high-molecular compounds. Acta of Bioengineering and Biomechanics. 2002, Vol. 4, Suppl.1, p. 703-704.

10. Goldade VA, Shalamov IV, Tsvetkova EA, Ukhartseva IY, Sementovskaya EA (1993) Phenomenological model of polarization process in low-conductive liquid-dispersed systems. Polymer composites-93: Collected papers of Intern. Conf., Gomel, 1993, p. 102103

11. Lyklema J (1987) Structure of solid/liquid interface and the electrical double layer. In Th.F. Tadros, Ed. Solid-Liquid Dispersions, Academic Press, London, 1987, p. 63-90

12. Lin Ch.-F, Lo Sh.-L, Wu Ch.-H (2006) Adsorption mechanisms of ion colloidal systems. In: P. Somasundaran, Ed. Encyclopedia of Surface and Colloid Science, Vol. 1, Taylor \& Francis, NW, 2006, p. 332410

13. Ukhartseva IY, Shalamov IV, Tsvetkova EA, Goldade VA (2000) Properties of ferrite filled systems based on high molecular compounds. 1 . Investigation of ferrite filled systems based on polyvinyl alcohol. Plastic Masses, 2000, No. 7, p. 5-8.

14. Tsvetkova EA, Shalamov IV, Ukhartseva IY, Goldade VA (2001) Properties of ferrite filled systems based on high molecular compounds. 2 . Polarization kinetic of low-conductive ferrite filled liquid-dispersed system based on alcohol solution of polyvinyl butiral. Plastic Masses, 2001, No. 11, p. 27-29.

15. Shalamov IV, Ukhartseva IY, Tsvetkova EA, Goldade VA (2002) A soft-hardware complex ASA-1 for controlling dispersed liquid systems. Instruments and Experimental Techniques. 2002, Vol. 45, No.6, p. 858-859.

16. Fomenko EB, Zholkovski EK, Deinega YF (1986) Surface-bulk charge and electric conductivity in liquid carbohydrates. Colloid Journal, 1986, Vol. 48, Issue 2, p. 377-380.

17. Vischuk NA, Dukhin SS (1990) Bulk charge of a conductive particle in the regime of maximum allowable current. Colloid Journal, 1990, Vol. 52, Issue 3, p. 497-501.

18. Sirota NN (1969) Thermodinamical and statistical physics. Minsk: Higher School, 1969, $470 \mathrm{p}$.

19. Gorokhovatski YA, Bordovski GA (1991) Thermally activated current spectroscopy of high-resistance semiconductors and dielectrics. Moscow: Science, 1991, 248 p. 